\title{
-Original-
}

\section{Evaluation of Hyperbaric Oxygen Therapy for Chronic Wounds}

\author{
Takashi Ueno ${ }^{1}$, Tokuya $\mathrm{Omi}^{2}$, Eiji Uchida ${ }^{3}$, \\ Hiroyuki Yokota $^{4}$ and Seiji Kawana ${ }^{1}$ \\ ${ }^{1}$ Department of Cutaneous and Mucosal Pathophysiology, Graduate School of Medicine, Nippon Medical School \\ ${ }^{2}$ Department of Dermatology, Queen’s Square Medical Facilities \\ ${ }^{3}$ Department of Surgery for Organ Function and Biological Regulation, Graduate School of Medicine, Nippon Medical School \\ ${ }^{4}$ Department of Emergency and Critical Care Medicine, Graduate School of Medicine, Nippon Medical School
}

\begin{abstract}
Background: Treating chronic wounds is challenging. Despite standard wound care, some chronic wounds fail to heal. Therefore, hyperbaric oxygen therapy (HBOT) was developed as an adjunct to standard wound care.

Objective: To evaluate the efficacy of HBOT for treating chronic wounds due to a variety of causes at our institution.

Methods: We reviewed the medical records of patients with chronic wounds treated with HBOT in addition to standard wound care at the Department of Dermatology, Nippon Medical School Hospital, from 2009 through 2012. Twenty-nine patients were reviewed (14 men and 15 women; mean age, $64.1 \pm 14.4$ years). The cause of chronic wounds was diabetes mellitus (DM) in 13 patients, venous stasis in 10, polyarteritis nodosa cutanea in 2, and livedoid vasculopathy, pyoderma gangrenosum, chronic renal failure, and systemic sclerosis in 1 patient each. The patients underwent HBOT for 60 minutes with $100 \%$ oxygen delivered via a mask in a hyperbaric chamber pressurized to 2.8 atmospheres of absolute pressure. The response of the chronic wounds to HBOT was evaluated according to the following criteria: "excellent": more than $90 \%$ wound healing; "good": a greater than $30 \%$ reduction in wound size, and wound healing was confirmed on follow-up visits within 6 weeks; "fair": wound healing was achieved with a combination of further invasive interventions; and "poor": the wound showed a less than $30 \%$ reducion or worsened during HBOT, or wound healing had not been completed by followup visits within 6 weeks.

Results: The response to HBOT was "excellent" in 6 patients, "good" in 8, "fair" in 11, and "poor" in 4. All 4 patients with a "poor" response had DM and had undergone hemodialysis.

Conclusions: HBOT is an effective treatment for patients with chronic wounds, due to a variety of causes, when used in combination with conventional standard therapy or further interventions. However, HBOT is less effective in patients with DM than in patients with venous stasis because hemodialysis, which is more common in patients with $\mathrm{DM}$, has negative effects on wound healing.
\end{abstract}

(J Nippon Med Sch 2014; 81: 4-11)

Key words: hyperbaric oxygen therapy, chronic wound, gangrene, ulcer, treatment

Correspondence to Takashi Ueno, MD, PhD, Department of Cutaneous and Mucosal Pathophysiology, Graduate School of Medicine, Nippon Medical School, 1-1-5 Sendagi, Bunkyo-ku, Tokyo 113-8603, Japan

E-mail: takashi-ueno@nms.ac.jp

Journal Website (http://www.nms.ac.jp/jnms/) 


\section{Introduction}

Chronic wounds are skin defects that are unlikely to heal within 6 weeks or that tend to recur frequently ${ }^{1}$. Treating chronic wounds is challenging. The principles of chronic wound care include moisture wound-healing preparation, infection control, debridement, proper dressings, and the use of common drugs, such as antibiotics and vasodilators. Despite appropriate standard care, some chronic wounds fail to heal. Therefore, additional treatments have been developed as adjuncts to standard care, including compression therapy, topical negative-pressure therapy, growth factor application, skin substitutes, and hyperbaric oxygen therapy $(\mathrm{HBOT})^{1}$. HBOT involves the administration of $100 \%$ oxygen at greater than 1 atmosphere of absolute pressure (ATA $)^{2.3}$. This article retrospectively evaluated the role of HBOT in the treatment of chronic wounds, due to a variety of causes, at our institution.

\section{Patients and Methods}

We reviewed the medical records of patients with chronic wounds treated with HBOT in addition to standard wound care at the Department of Dermatology, Nippon Medical School Hospital from 2009 through 2012. Patients whose wounds persisted for 6 weeks or longer or recurred numerous times were defined as having chronic wounds. The standard wound care included cleansing, debridement of necrotic tissue, maintenance of a moist wound environment, and the administration of antibiotics, vasodilators, or anticoagulants. The patients underwent HBOT with exposure for 60 minutes with $100 \%$ oxygen delivered via a mask in a hyperbaric chamber (Hanyuda Co., Ltd., Nagano, Japan) pressurized to 2.8 ATA. The HBOT sessions were performed once daily 3 to 5 days a week. Only patients who had undergone 5 or more sessions of HBOT were included in this study. The original diseases, affected sites, and clinical courses were recorded. Twenty-nine patients were reviewed (Table 1). The subjects were 14 men and 15 women aged 29 to 80 years (mean age, $64.1 \pm 14.4$ years). The duration of the lesions was 2.5 to 84 months (mean duration, $10.2 \pm 16.2$ months). The original cause of chronic wounds was diabetes mellitus (DM) in 13 patients, venous stasis in 10 , polyarteritis nodosa cutanea in 2, and livedoid vasculopathy, pyoderma gangrenosum, chronic renal failure (CRF), and systemic sclerosis in 1 patient each. Of these patients, 5 with diabetes, 1 with polyarteritis nodosa cutanea, and the patient with $\mathrm{CRF}$ had undergone hemodialysis. Of the 7 patients who had undergone dialysis, 1 patient with diabetes and the patient with $\mathrm{CRF}$ had calciphylaxis. The mean number of HBOT sessions was 22 , and the maximum number was 57 .

The response of the chronic wounds to HBOT was evaluated according to the following criteria: "excellent": wound healing was complete, or more than $90 \%$ epithelization was obtained at the end of HBOT; "good": a greater than 30\% reduction in wound size was obtained at the end of HBOT, and wound healing was confirmed on follow-up visits within 6 weeks; "fair": wound healing was achieved with a combination of further invasive interventions, such as skin grafting, percutaneous transluminal angioplasty, vein stripping, or digital amputation, to remove the necrotic tissue; and "poor": the wound showed a less than $30 \%$ reduction or worsened during HBOT, or wound healing had not been completed by follow-up visits within 6 weeks.

\section{Results}

\section{Presentation of Typical Cases}

1. Patient 15, a 78-year-old women, developed a venous stasis ulcer on the left leg (Fig. 1a). Despite being treated with standard wound care for 5 months, the wound did not heal (Fig. 1b). Therefore, HBOT was added to treat the wound. After 45 sessions of HBOT, the wound had almost completely epithelized (Fig. 1c). The response to HBOT was evaluated as "excellent."

2. Patient 19, a 69-year-old man, had an 8-month history of stasis ulcers on the left leg (Fig. 2a, b). He underwent 8 sessions of HBOT in addition to receiving standard wound care. Wound healing with epithelization was confirmed at the follow-up visit 6 
T. Ueno, et al

Table 1 Patients with chronic wounds treated with HBOT

\begin{tabular}{|c|c|c|c|c|c|c|c|c|c|}
\hline Patient & $\begin{array}{c}\text { Age } \\
\text { (years) }\end{array}$ & Sex & $\begin{array}{l}\text { Causative } \\
\text { disease }\end{array}$ & Site & $\begin{array}{c}\text { Duration of } \\
\text { lesions } \\
\text { (months) }\end{array}$ & $\begin{array}{l}\text { HBOT } \\
\text { sessions }\end{array}$ & $\begin{array}{c}\text { Further } \\
\text { intervention }\end{array}$ & Result & $\begin{array}{c}\text { Adverse effect/ } \\
\text { treatment }\end{array}$ \\
\hline 1 & 65 & $\mathrm{~F}$ & $\mathrm{DM}$ & Foot & 3 & 15 & & Excellent & \\
\hline 2 & 73 & $\mathrm{~F}$ & $\mathrm{DM}$ & Foot & 3 & 6 & & Good & \\
\hline 3 & 73 & $\mathrm{M}$ & $\mathrm{DM}$ & Toe & 2.5 & 15 & & Good & \\
\hline 4 & 30 & $\mathrm{~F}$ & $\mathrm{DM} / \mathrm{HD}$ & Toe & 4 & 24 & & Good & \\
\hline 5 & 65 & $\mathrm{M}$ & $\mathrm{DM}$ & Foot & 6 & 22 & PTA & Fair & \\
\hline 6 & 66 & $\mathrm{M}$ & $\mathrm{DM}$ & Foot & 84 & 31 & digital amputation & Fair & \\
\hline 7 & 68 & $\mathrm{M}$ & DM & Foot & 5 & 36 & PTA & Fair & \\
\hline 8 & 66 & $\mathrm{M}$ & $\mathrm{DM}$ & Foot & 4 & 14 & $\begin{array}{l}\text { digital amputation/ } \\
\text { skin graft }\end{array}$ & Fair & \\
\hline 9 & 69 & $\mathrm{M}$ & $\mathrm{DM}$ & Toe & 4 & 18 & $\begin{array}{l}\mathrm{PTA} / \text { digital } \\
\text { amputation }\end{array}$ & Fair & $\begin{array}{c}\text { otitis/ } \\
\text { myringotomy* }\end{array}$ \\
\hline 10 & 68 & $\mathrm{M}$ & $\mathrm{DM} / \mathrm{HD}$ & Foot & 3 & 20 & & Poor & \\
\hline 11 & 50 & $\mathrm{M}$ & $\begin{array}{l}\mathrm{DM} / \mathrm{HD} / \\
\text { calciphylaxis }\end{array}$ & Toe & 4 & 22 & & Poor & \\
\hline 12 & 72 & $\mathrm{~F}$ & $\mathrm{DM} / \mathrm{HD}$ & Toe & 5 & 9 & & Poor & \\
\hline 13 & 66 & $\mathrm{M}$ & $\mathrm{DM} / \mathrm{HD}$ & Finger & 5 & 45 & & Poor & \\
\hline 14 & 75 & $\mathrm{~F}$ & $\begin{array}{l}\text { Venous } \\
\text { stasis }\end{array}$ & Leg & 7 & 6 & & Excellent & \\
\hline 15 & 78 & $\mathrm{~F}$ & $\begin{array}{l}\text { Venous } \\
\text { stasis }\end{array}$ & Leg & 40 & 45 & & Excellent & \\
\hline 16 & 80 & $\mathrm{~F}$ & $\begin{array}{l}\text { Venous } \\
\text { stasis }\end{array}$ & Leg & 8 & 17 & & Excellent & otitis/tubing \\
\hline 17 & 77 & $\mathrm{~F}$ & $\begin{array}{l}\text { Venous } \\
\text { stasis }\end{array}$ & Leg & 5 & 11 & & Good & \\
\hline 18 & 71 & $\mathrm{~F}$ & $\begin{array}{l}\text { Venous } \\
\text { stasis }\end{array}$ & Leg & 14 & 27 & & Good & \\
\hline 19 & 69 & M & $\begin{array}{l}\text { Venous } \\
\text { stasis }\end{array}$ & Leg & 13 & 8 & & Good & \\
\hline 20 & 44 & $\mathrm{~F}$ & $\begin{array}{l}\text { Venous } \\
\text { stasis }\end{array}$ & Leg & 32 & 13 & skin graft & Fair & \\
\hline 21 & 76 & $\mathrm{~F}$ & $\begin{array}{l}\text { Venous } \\
\text { stasis }\end{array}$ & Leg & 4 & 23 & $\begin{array}{l}\text { stripping/skin } \\
\text { graft }\end{array}$ & Fair & \\
\hline 22 & 47 & $\mathrm{M}$ & $\begin{array}{l}\text { Venous } \\
\text { stasis }\end{array}$ & Leg & 6 & 51 & skin graft & Fair & \\
\hline 23 & 77 & $\mathrm{~F}$ & $\begin{array}{l}\text { Venous } \\
\text { stasis }\end{array}$ & Foot & 8 & 57 & skin graft & Fair & \\
\hline 24 & 79 & $\mathrm{M}$ & $\mathrm{PG}$ & Multiple & 5 & 36 & & Excellent & \\
\hline 25 & 29 & $\mathrm{~F}$ & $\begin{array}{c}\text { Livedoid } \\
\text { vasculopathy }\end{array}$ & Foot & 2.5 & 14 & & Excellent & \\
\hline 26 & 70 & $\mathrm{M}$ & $\mathrm{PNC} / \mathrm{HD}$ & Toe & 3 & 16 & & Good & \\
\hline 27 & 53 & $\mathrm{~F}$ & $\mathrm{SSc}$ & Finger & 6 & 5 & & Good & \\
\hline 28 & 68 & $\mathrm{~F}$ & PNC & Toe & 4 & 38 & digital amputation & Fair & \\
\hline 29 & 34 & $\mathrm{M}$ & $\begin{array}{l}\mathrm{CRF} / \mathrm{HD} / \\
\text { calciphylaxis }\end{array}$ & Finger & 6 & 8 & PTA & Fair & \\
\hline
\end{tabular}

Note

HBOT: Hyperbaric oxygen therapy

DM: Diabetes mellitus

SSc: Systemic sclerosis

HD: Hemodialysis

PG: Pyoderma gangrenosum PTA: Percutaneous transluminal angioplasty

PNC: Cutaneous polyarteritis nodosa CRF: Chronic renal failure

* Patient 9 restarted HBOT after myringostomy.

weeks later. The wound continued to be epithelized 2 years later (Fig. 2c, d). The response to HBOT was evaluated as "good."

3. Patient 8, a 65-year-old man, had diabetic gangrene of the fourth toe and lateral margin of the left foot (Fig. 3a). Necrosis of the lesion had developed; therefore, the fourth and fifth toes were amputated (Fig. 3b), and 14 sessions of HBOT were performed. The wound was covered with granulation tissue and then grafted with full- 

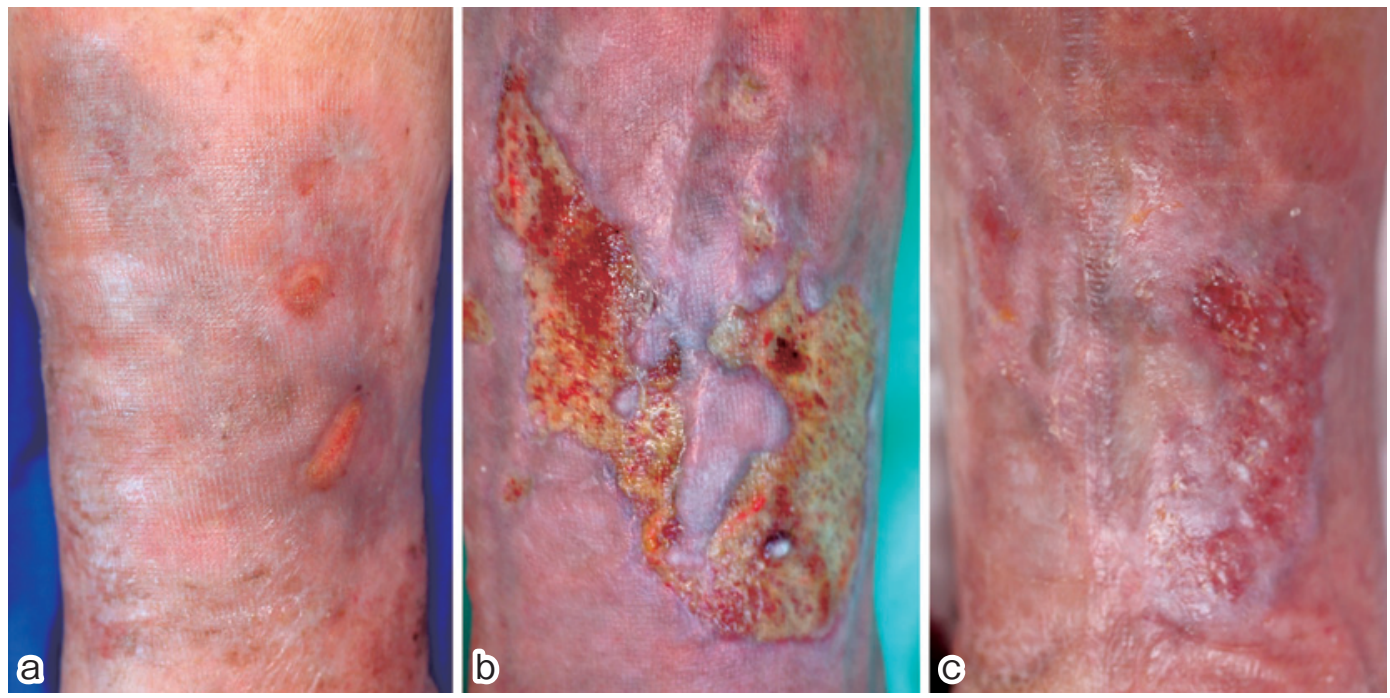

Fig. 1 Patient 15, who had a venous stasis ulcer on the left leg (a). Despite standard therapy, the wound would not heal (b). After 45 sessions of HBOT, the wound was almost completely epithelized (c).
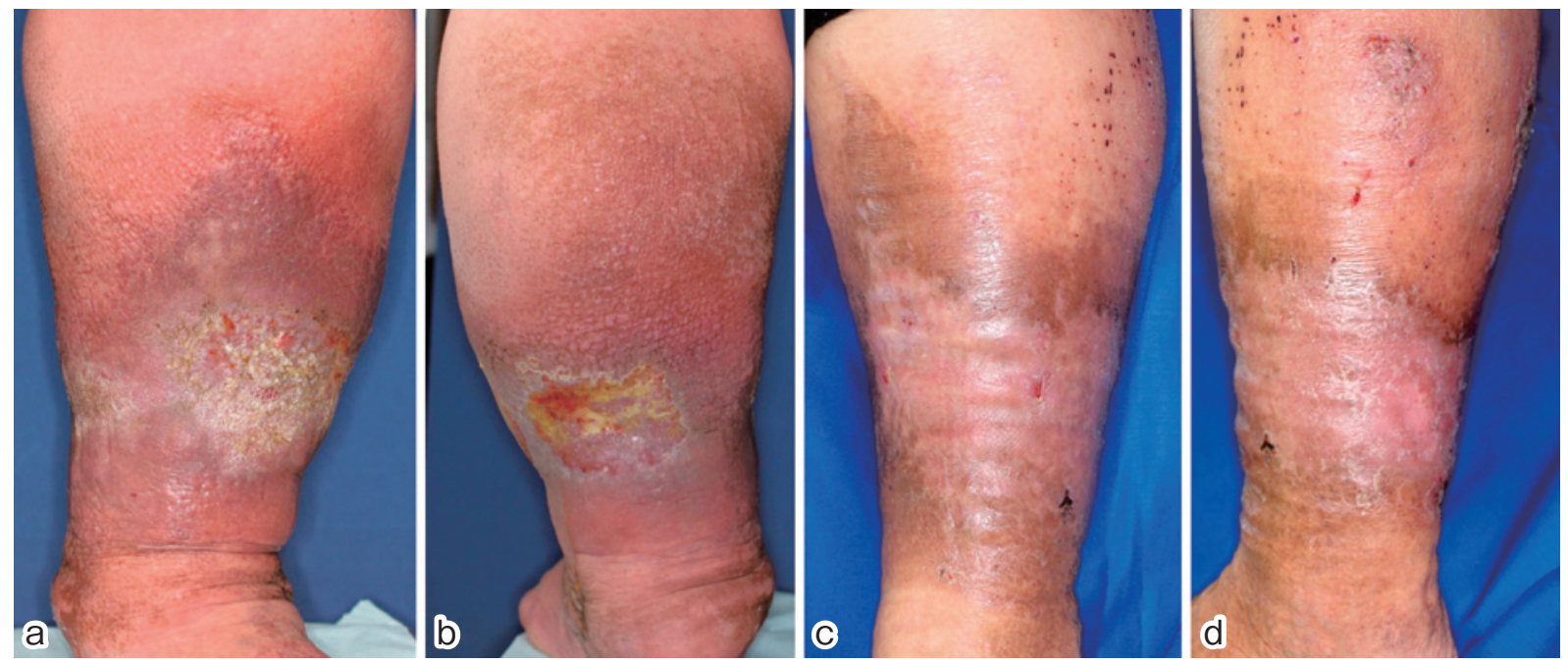

Fig. 2 Patient 19, who had stasis ulcers on the left leg (a, b). The combination of HBOT and standard wound care led to epithelization by the follow-up visit. The wound was still epithelized 2 years later (c, d).

thickness skin. The wound was still stable after 5 months (Fig. 3c). The response to HBOT was evaluated as "fair."

4. Patient 11, a 50-year-old man who had DM and was undergoing hemodialysis, had necrosis of the third and fifth toes of the right foot (Fig. 4a). Calciphylaxis also developed. He underwent amputation of both toes (Fig. $\mathbf{4 b}$ ) and 22 sessions of HBOT. Despite receiving this treatment, a necrotic wound developed in the surrounding tissue, including the fourth toe (Fig. 4c). The response to HBOT was evaluated as "poor."

\section{Overall Response Evaluation}

The response to HBOT was evaluated as "excellent" in 6 patients, "good" in 8, "fair" in 11, and "poor" in 4 (Table 1). Of the 11 patients with "fair" responses, 5 underwent skin grafting, 4 underwent digital amputation to remove gangrenous tissue, 4 underwent percutaneous transluminal angioplasty, and 1 underwent vein stripping, including overlapping. All 4 patients with "poor" responses had DM and received dialysis owing to diabetic renal failure. One of these 4 patients had calciphylaxis. 

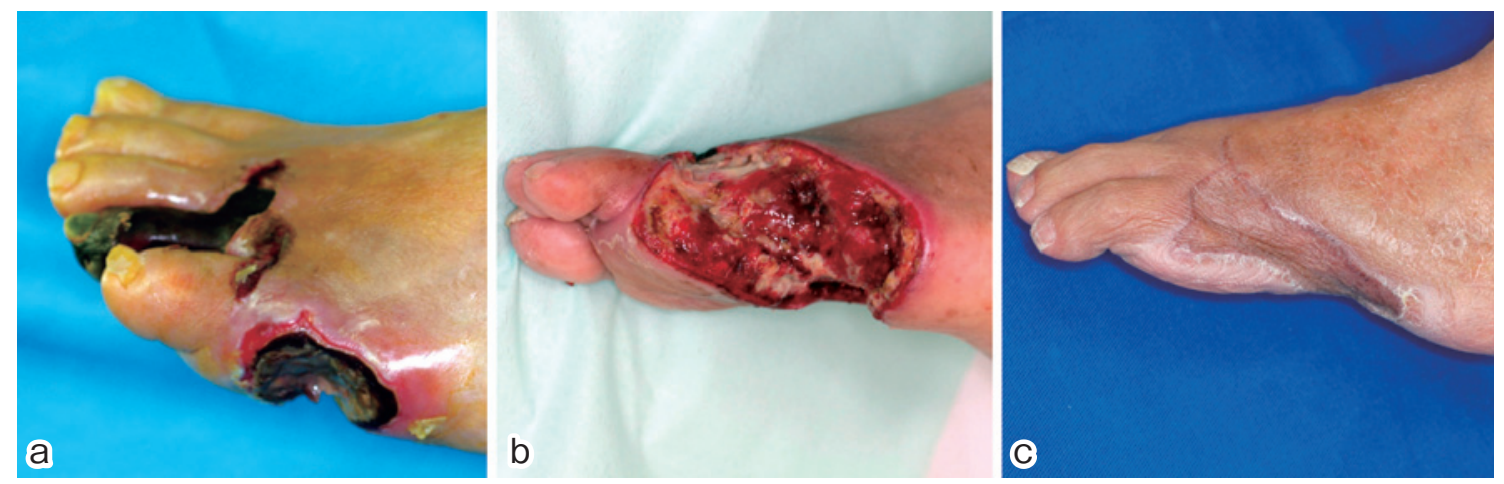

Fig. 3 Patient 8, who had diabetic gangrene of the fourth toe and lateral margin of the left foot (a). The fourth and fifth toes were amputated (b). Fourteen sessions of HBOT and skin grafting induced wound closure that remained stable after 5 months (c).
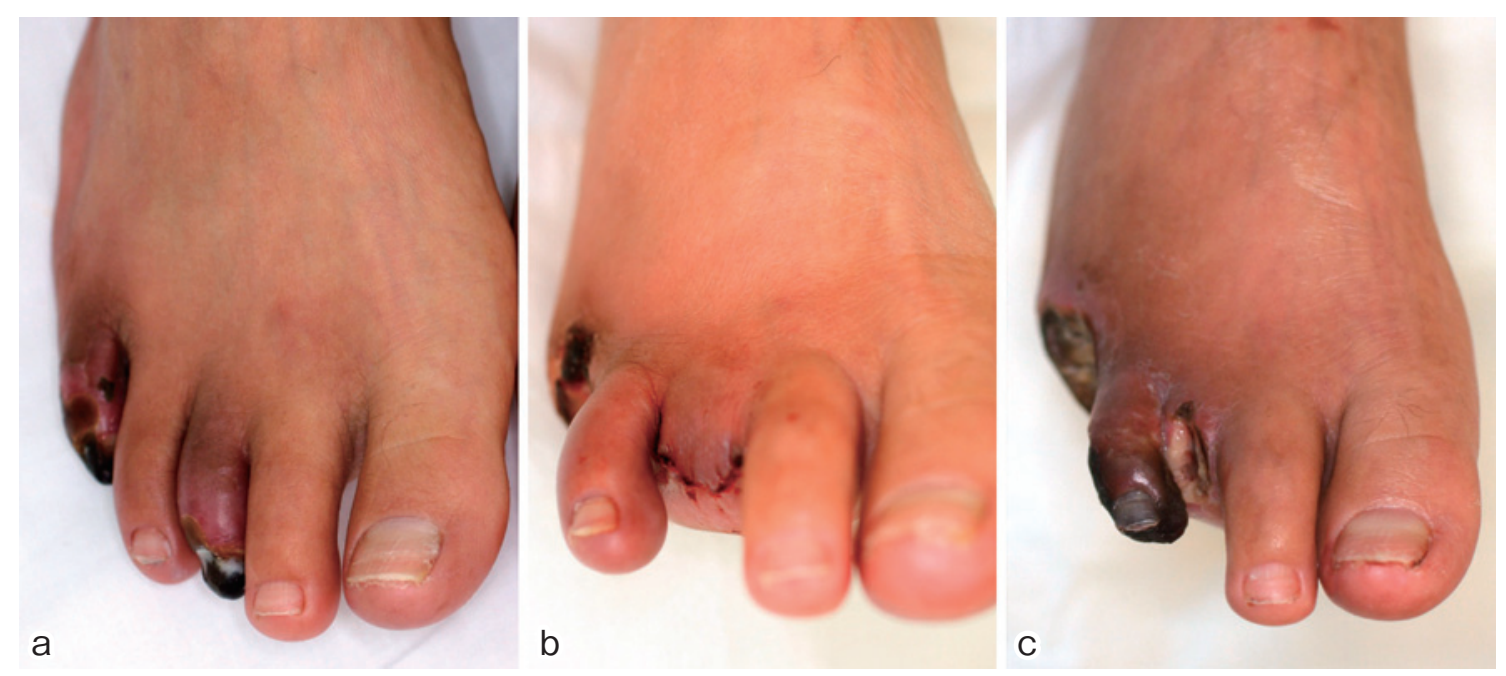

Fig. 4 Patient 11, who had DM and calciphylaxis and was undergoing hemodialysis, developed necrosis of the third and fifth toes (a). Both toes were amputated (b). Despite HBOT, a necrotic wound developed (c).

\section{Adverse Effects}

Two patients contracted barotraumatic otitis. One patient had otitis during the treatment session, developed myringotomy, and was treated with HBOT a second time. Another patient developed otitis after receiving HBOT and was treated with insertion of a tube to equalize the ear pressure. No other adverse effects were observed.

\section{Discussion}

The concentration of oxygen in wounds is a controlling factor in various processes that are impaired under conditions of tissue hypoxia ${ }^{23}$. A significant increase in oxygen diffusion around arterioles during HBOT enhances tissue oxygenation, as long as a certain level of circulation is ensured ${ }^{2}$. This phenomenon helps to improve various symptoms ${ }^{3}$.

HBOT has been reported to promote optimal conditions for wound healing. Some elements of tissue repair are extremely oxygen-dependent, for example collagen elaboration and deposition by fibroblasts. ${ }^{4}$. Mader et al..$^{5}$ have demonstrated that HBOT is at least as effective as antibiotic therapy for treating osteomyelitis in rabbits. Marx et $\mathrm{al}^{6}$ have reported angiogenesis due to increased vascular density following HBOT in an irradiated rabbit model. Tompach et al. ${ }^{7}$ exposed cultured endothelial cells and fibroblasts to hyperbaric oxygen and documented increased proliferation of both cell types. Epithelial migration is 
enhanced by adequate wound oxygenation; thus, reepithelialization is oxygen-mediated ${ }^{3}$. Furthermore, hyperoxia causes vasoconstriction, which decreases edema in the periwound area $^{8}$. These studies suggest that HBOT contributes to the woundhealing process.

In routine clinical application, HBOT is administered in repetitive sessions, with pressure and time limits of 3.0 ATA and 120 minutes, respectively. This short duration of treatment can prevent potential complications of oxygen toxicity, the most feared of which is acute central nervous system oxygen toxicity, presenting as generalized seizures. However, despite the short duration of treatment, the arterial and soft-tissue partial pressures of oxygen $\left(\mathrm{pO}_{2}\right)$ remain elevated for 2 to 4 hours after the completion of HBOT $^{2,3}$.

Several researchers have investigated the use of HBOT for treating chronic wounds in patients with DM. The most important factors in treating these wounds are peripheral arterial disease and peripheral neuropathy ${ }^{9}$. Baroni et al. $^{10}$ treated patients with diabetic foot gangrene (including patients with macroangiopathy) and reported that those treated with HBOT were less likely to undergo amputation than those not treated. Abidia et $\mathrm{al}^{9}{ }^{2}$ have evaluated the role of HBOT in the management of ischemic lower-extremity ulcers in patients with DM; they concluded that HBOT enhances wound healing and is a valuable adjunct to conventional therapy. Duzgun et al. ${ }^{11}$ have performed a prospective, randomized study of HBOT versus standard wound care in the treatment of diabetic foot ulcers. They noted that patients treated with HBOT were more likely to show wound healing and less likely to undergo amputation proximal to the metatarsophalangeal joint than were patients receiving standard treatment ${ }^{11}$.

Our present study included 13 patients with DM. Of these patients, only 1 (8\%) had an "excellent" response, and 3 (23\%) had a "good" response. Therefore, HBOT was effective for 31\% (4 of 13) of patients with diabetic ulcers. These results reflect poorer outcomes than in previous studies. Our poorer outcomes are partially attributable to the fact that 5 patients with DM exhibited a "good” response.
These 5 cases may have interfered with a rigorous assessment because the prognoses of such cases cannot be determined without further interventions. This study was retrospective, not prospective; therefore, as a matter of course, certain patients were additionally treated with effective measures depending on the individual's condition. On the other hand, all 4 patients who exhibited a "poor" response had DM. However, these "poor" responses can be attributed to the fact that all of these patients underwent hemodialysis and that 1 patient also developed calciphylaxis. Patients with DM who undergo hemodialysis have further risk factors for poor wound healing, such as uremia, vascular calcification, uremic neuropathy, susceptibility to infection, hypoalbuminemia, and abnormal plasma zinc levels ${ }^{12}$.

With respect to venous leg ulcers, Bass ${ }^{13}$ reported in 1970 that $89 \%$ (17 of 19) of patients treated with HBOT had complete healing of ulcers. Hammarlund and Sundberg ${ }^{14}$ have compared the effects of HBOT with those of hyperbaric air on chronic wound healing and found that HBOT is a valuable adjunct therapy. McEwen and Smith ${ }^{15}$ have advocated the use of HBOT as an adjunct treatment for chronic venous ulcers. The effectiveness of HBOT for chronic venous ulcers is attributed to the attenuation of leukocyte dysfunction, the reduction of edema, and the stimulation of capillary and collagen formation ${ }^{15}$. Of the 10 patients with venous stasis included in our series, 3 had an "excellent" response and 3 had a "good" response. The remaining 4 patients also demonstrated wound healing after being treated with further combined interventions, that is, skin grafting or stripping of varicose veins. All patients with venous stasis ultimately demonstrated complete wound healing. These results confirm the usefulness of HBOT as an adjunct therapy for treating chronic wounds caused by venous stasis, as previously suggested ${ }^{13-15}$.

Heng $^{16}$ has reported that abundant granulation tissue was induced with topical HBOT in a patient with polyarteritis nodosa. Efrati et al. ${ }^{18}$ evaluated the effects of HBOT in 35 patients with vasculitisinduced nonhealing skin ulcers. The types or causes of vasculitis included cutaneous leukocytoclastic 
vasculitis, systemic lupus erythematosus, rheumatoid arthritis, inflammatory bowel disease, mixed connective tissue disease, Henoch-Schönlein purpura, giant cell arteritis, and mixed cryoglobulinemia. They concluded HBOT is a safe and effective treatment for patients with vasculitis and nonhealing skin ulcers ${ }^{18}$. Markus et al. ${ }^{19}$ have reported 2 cases of scleroderma wounds that were successfully treated with HBOT. In the present study, 1 patient with polyarteritis nodosa cutanea and 1 patient with systemic sclerosis had "good" responses. These results support the findings of earlier studies. Remarkably, in the present study, "excellent" responses were shown by a patient with pyoderma gangrenosum and a patient with livedoid vasculopathy. Davis et al. ${ }^{17}$ used HBOT to prepare wounds for skin grafting in 4 patients with pyoderma gangrenosum and reported that each wound responded to $\mathrm{HBOT}$, that the rate of infection decreased, and that capillary angiogenesis increased. Pyoderma gangrenosum does not fall within the spectrum of circulatory dysfunctions but belongs to the category of neutrophilic dermatoses ${ }^{20}$. The effect of hyperbaric oxygen on neutrophil activity $^{3}$ might help explain the usefulness of HBOT for treating pyoderma gangrenosum. Yang et $\mathrm{al}^{21}$ used HBOT to treat patients with livedoid vasculopathy of the toes and reported a rapid response of the ulcers to therapy and the resolution of wound pain. They concluded that HBOT is a promising therapy for patients with livedoid vasculopathy. Livedoid vasculopathy is a type of thrombo-occlusive vasculopathy, and the efficacy of HBOT in treating this condition is ascribed not only to increased tissue oxygenation around the wound but also to the effects on fibrinolytic factors ${ }^{21}$. In the present study, 2 patients developed calciphylaxis, 1 of whom had DM. The responses to HBOT in these 2 patients were not judged "excellent" or "good" because calciphylaxis is a serious final stage of renal failure that progresses to refractory ulcers and gangrene. Furthermore, several investigators have reported the role of HBOT in treating select patents with calciphylaxis ${ }^{22,23}$.

Two patients in the present study developed otitis due to HBOT. During the compression phase of
HBOT, pressure in the sinus cavities must be equalized. Barotrauma, especially to the middle ear, is the most common complication, although it is usually mild ${ }^{8}$. The 2 patients in our series with otitis recovered quickly with ontological treatment.

In summary, we treated patients with chronic wounds due to a variety of causes, including DM and venous stasis. Our results suggest that HBOT is an effective treatment for chronic wounds due to a variety of causes when used in combination with conventional standard therapy or further interventions. However, HBOT is less effective for the treatment of chronic wounds in patients with DM than in those with venous stasis. This decreased effectiveness is due to hemodialysis, which is more common in patients with DM and can have additional negative effects on wound healing.

Conflict of Interest: The authors declare that there is no conflict of interest.

\section{References}

1. Fonder MA, Lazarus GS, Cowan DA, Aronson-Cook B, Kohli AR, Mamelak AJ: Treating the chronic wound: A practical approach to the care of nonhealing wounds and wound care dressings. J Am Acad Dermatol 2008; 58: 185-206.

2. Gimbel M, Hunt T: Wound healing and hyperbaric oxygenation. In Hyperbaric medicine practice (Kindwall EP, Whelan HT, eds), 2nd ed. 1999; pp 169204, Best Publishing Company, Flagstaff (AZ).

3. Boykin JV: Hyperbaric oxygen therapy: a physiological approach to selected problem wound healing. Wounds 1996; 8: 183-198.

4. Hunt TK, Niinikoski J, Zederfeldt B: Role of oxygen in repair processes. Acta Chir Scand 1972; 138: 109110.

5. Mader JT, Guckian JC, Glass DL, Reinarz JA: Therapy with hyperbaric oxygen for experimental osteomyelitis due to Staphylococcus aureus in rabbits. J Infect Dis 1978; 138: 312-318.

6. Marx RE, Ehler WJ, Tayapongsak P, Pierce LW: Relationship of oxygen dose to angiogenesis induction in irradiated tissue. Am J Surg 1990; 160: 519-524.

7. Tompach PC, Lew D, Stoll JL: Cell response to hyperbaric oxygen treatment. Int J Oral Maxillofac Surg 1997; 26: 82-86.

8. Roth RN, Weiss LD: Hyperbaric oxygen and wound healing. Clin Dermatol 1994; 12: 141-156.

9. Abidia A, Laden G, Kuhan G, et al.: The role of hyperbaric oxygen therapy in ischaemic diabetic lower extremity ulcers: a double-blind randomisedcontrolled trial. Eur J Vasc Endovasc Surg 2003; 25: 
$513-518$

10. Baroni G, Porro T, Faglia E, et al.: Hyperbaric oxygen in diabetic gangrene treatment. Diabetes Care 1987; 10: 81-86.

11. Duzgun AP, Satir HZ, Ozozan O, Saylam B, Kulah B, Coskun F: Effect of hyperbaric oxygen therapy on healing of diabetic foot ulcers. J Foot Ankle Surg 2008; 47: 515-519.

12. Lewis S, Raj D, Guzman NJ: Renal Failure: Implications of Chronic Kidney Disease in the Management of the Diabetic Foot. Semin Vasc Surg 2012; 25: 82-88.

13. Bass BH: The treatment of varicose leg ulcers by hyperbaric oxygen. Postgrad Med J 1970; 46: 407408.

14. Hammarlund C, Sundberg T: Hyperbaric oxygen reduced size of chronic leg ulcers: a randomised double blind study. Plastic Reconstr Surg 1994; 93: 829-834.

15. McEwen AW, Smith MB: Chronic venous ulcer. Hyperbaric oxygen treatment is a cost effective option. BMJ 1997; 315: 188-189.

16. Heng MC: Hyperbaric oxygen therapy for a foot ulcer in a patient with polyarteritis nodosa. Australas J Dermatol 1983; 24: 105-108.

17. Davis JC, Landeen JM, Levine RA: Pyoderma gangrenosum: skin grafting after preparation with hyperbaric oxygen. Plast Reconstr Surg 1987; 79:
200-207.

18. Efrati S, Bergan J, Fishlev G, Tishler M, Golik A, Gall $\mathrm{N}$ : Hyperbaric oxygen therapy for nonhealing vasculitic ulcers. Clin Exp Dermatol 2007; 32: 12-17.

19. Markus YM, Bell MJ, Evans AW: Ischemic scleroderma wounds successfully treated with hyperbaric oxygen therapy. J Rheumatol 2006; 33: 1694-1696.

20. Weenig RH, Davis MD, Dahl PR, Su WP: Skin ulcers misdiagnosed as pyoderma gangrenosum. N Engl J Med 2002; 347: 1412-1418.

21. Yang CH, Ho HC, Chan YS, Liou LB, Hong HS, Yang LC: Intractable livedoid vasculopathy successfully treated with hyperbaric oxygen. Br J Dermatol 2003; 149: 647-652.

22. Basile C, Montanaro A, Masi M, Pati G, De Maio P, Gismondi A: Hyperbaric oxygen therapy for calcific uremic arteriolopathy: a case series. J Nephrol 2002; 15: $676-680$.

23. Arenas MD, Gil MT, Gutiérrez MD, et al:: Management of calcific uremic arteriolopathy (calciphylaxis) with a combination of treatments, including hyperbaric oxygen therapy. Clin Nephrol 2008; 70: 261-264.

(Received, May 14, 2013)

(Accepted, June 5, 2013) 